\title{
Development of Central Skull Base of the One Humped Camel (Camelus dromedarius): Dissection, CT, MRI and Plain Radiography of Ossification
}

\section{Centers}

\author{
K.M. Shoghy and A.S. Saber
}

Department of Anatomy \& Embryology, Faculty of Vet. Med., University of Sadat City, EGYPT

Received March, accepted for publication April 2015

\section{Abstract}

The central skull base (chondrocranium) is formed by the occipital and sphenoid bones. The development of fetal skull base has previously been studied in most mammals, but in the camel it is still obscure. So, the aim of this study is to follow the development of the central skull base and synchondrosis of its ossification centers in the one humped camel (Camelus dromedarius) from the anatomical and embryological point of view through the normal dissection and by using the different imaging techniques (computed tomography (CT), magnetic resonance (MR) imaging and plain radiographic techniques.

Knowledge from this research will give an idea about the morphogenesis of the skull base in relation to the enclosed vital organs.

Keywords: Central skull base, Development, CT, Camel

\section{Introduction}

The development and anatomy of the central skull base was previously studied in most mammals (Moore, 1981; Noden, 1991; Couly et al. 1993; Van Dermwe et al., 1995; Depew et al., 2002 and Yoshida et al. 2008); however, in the camel it is still obscure.

Therefore, the aim of this study is to follow the development of the central skull base and synchondrosis of its ossification centers in the one humped camel (Camelus dromedarius) from the anatomical and embryological point of view. This follow is achieved by the normal dissection and by using the different imaging techniques (computed tomography (CT), magnetic resonance (MR) imaging and plain radiographic techniques. The central skull base (chondrocranium) is formed by the occipital and sphenoid bones. These bones are preformed in cartilage (Scheuer and Black, 2000 and Standring, 2005). 
Occipital bone (Os occipitale)

The developing occipital bone is composed of squamous, basilar, and paired ex-occipital segments (Williams, 1995 and König \& Liebich, 2004). In horse, the occipital bone ossified in cartilage from 4 centers, and consists, at birth, of four segments as described above. The lateral parts united with the basilar part at 3-4 months of age, and with the squamous part in the 2nd year of age. The lambdoidal (parieto-occi-pital) suture and the spheno-occipital synchondrosis were obli-terated at about $5^{\text {th }}$ year of age. The occipito-mastoid suture partially ossified in old subjects (Hillmann, 1975).

In camel, of the occipital group of bones the supra-occipital is the first to ossify from the cartilaginous primordium. In the $3.1 \mathrm{~cm} \mathrm{H.H.} \mathrm{(Head} \mathrm{Height)}$ specimen two small patches of ossification develop in the condylar portion of the lateral part, separated by a considerable distance. In the parachordal region the basi-occipi-tal appears as a median pair of oval shaped bodies placed on either side of the midline (Kanan, 1962).

Sphenoid bone (Os sphenoidale) (Os basisphenoidale) and (Os presphenoidale). The sphenoid bone consists, at birth, of two distinct parts, the basisphenoid and the presphenoid. The basisphenoid is composed of a body, a pair of wings and a pair of pterygoid processes. The presphenoid is composed of a body and a pair of wings (orbitosphe-noids) J. Vet. Anat.
(Hillmann, 1975, Williams, 1995, Scheuer and Black, 2000 and König \& Liebich, 2004).

Hillmann (1975) stated that the sephenoid bone of the horse was ossified in cartilage. He added that the presphenoid developed from two centers, one for each wing. While the basisphenoid developed from three centers, one for the body and one for each wing. The pterygoid processes ossified from the centers of the wings of the basisphenoid.

In camel, the ossification centers for the basisphenoid appear first in the $3.5 \mathrm{~cm} \mathrm{H.H}$. specimen, as a single median rounded body. The presphenoid appears at first in the $3.7 \mathrm{~cm} \mathrm{H}^{\prime} \mathrm{H}^{\prime}$ specimen as a pair of crescent shaped bodies placed medial to the optic foramen (Kanan, 1962).

\section{Materials and Methods Materials}

1- Fifteen skulls of camel fetuses of both sexes ranging from 33.5 to $84 \mathrm{~cm}$ CVR length. The gestational stage was estimated on the basis of crown vertebral rump CVR length (El-Wishy et al., 1981).

2- Eight skulls of young and adult camels aged 2.5, 3, $7.5-8$ and over 12 years used for tracing the suture closure of the central skull base. The age was estimated by dentition according to Rabigliata (1924).

\section{Methods}

Ten formalin-fixed fetal skulls of normal fetuses were examined with CT,
Vol. 8, No. 2, (2015) 1 - 16 
$\mathrm{MRI}$ and plain radiography (6 fetuses were examined with $\mathrm{CT}$, and 1 with $\mathrm{MRI}$ and 3 with plain radiography). The fetal skulls were dissected carefully by normal technique before further observations.

A Toshiba CT unit was used to scan the specimens with 3-mm-thick contiguous slices, the exposure values was $\mathrm{KV}=130$, and $\mathrm{MAs} / \mathrm{ref}=30 / 81$.

A GE medical system 1.5-T clinical unit was used for the MR imaging. Short tau inversion recovery (STIR) had the following parameters: (1168/70/16), $512 \times 384$ matrix, and $3.0-\mathrm{mm}$-thick sections with a $0.5-\mathrm{mm}$ section gap.

The radiographic examination was performed with high definition and mamofilms. The exposure values was $\mathrm{KV}=42-50, \mathrm{MA}=100$ and $\mathrm{MAs}=$ 30 according to skull dimensions.

The examined specimens were photographed by digital camera, Sony 6 mega pixels, Dsc - w 50.

\section{Results}

\section{Occipital bone (Os occipitale)}

\section{At 33.5 - $37 \mathrm{~cm}$ CVRL camel fetus- es:}

The occipital bone develops in seven ossification centers investigated by normal dissection and different imaging techniques; two for the lateral part (exo-occipitals), two for the basioccipital part and three for the squamous part (Figs. 1, 2, 21, 23, 24, 25, $26,27)$.
The occipital condyles have a quadrilateral shape, obliquely placed, and separated dorsally by wide space and ventrally by a relatively narrow interval (Fig 1).

A short wide plate-like process projects ventrally lateral to the occipital condyles, the paramastoid or jugular process, which has convex lateral surface and concave medial surface (Fig 1). Between the root of the jugular process and the occipital condyle is the condyloid fossa (Fig 1).

The basi-occipital part appears in transverse and coronal sections of CT scan especially in the caudal part even in the advanced stage of the development as a median pair of oval shaped bodies placed on either side of the midline (Fig 24).

The basi-occipital part appears in this stage as a flattened bar, wide caudally and narrow rostrally (Fig 2). The caudal end of the bar has two lateral obliquely directed surfaces, each for the attachment with the corresponding occipital condyle by a layer of cartilage (Fig 2).

The external surface of the squamous part is crossed by a prominent line forming a low ridge, the nuchal crest, which divides the surface into two unequal parts; the large dorsal area (parietal part) and small ventral area (supra-occipital part or nuchal part) (Fig $3)$.

The parietal part ossifies from a single center while the supra-occipital part ossifies from double centers (Fig 2). 
No fusion is occurred among these centers at this stage.

\section{At 48.5 - $58 \mathrm{~cm}$ CVRL camel fetus- es:}

The basi-occipital shows an increased area of ossification but neither the occipital condyles nor the basi-occipital have established contact with the neighboring bones; all of them remain isolated from each other (Figs. 4, 5).

The supra-occipital part shows an increased area of ossification and establishes fusion with the parietal part but both centers are still separated from each other by a layer of cartilage (Fig 6).

\section{At 71 - $84 \mathrm{~cm}$ CVRL camel fetuses:}

The fusion between occipital condyles and the basi-occipital begins at $71 \mathrm{~cm}$ CVRL of camel fetus and completes the fusion with each other at $84 \mathrm{~cm}$ CVRL of camel fetus (Fig7). The basioccipital is still connected with the body of the basi-sphenoid by a thin layer of cartilage (Fig 7).

The parietal border of the squamous part unites in a great extent with the parietal bone by the occipito-parietal suture and joins in small extent the squamous part of the temporal bone at the squamo-occipital suture (Fig 8). The ex-occipitals unite with the supraoccipital part by transverse sutures (Fig 9).

\section{At 2.5 - 3 years of age of the camel:} The supra-occipital part of the squamous part of the occipital bone fuses completely with the ex-occipitals, which they are still joining together by a sagittal suture (Fig 10). It has a prominent external occipital protuberance. The jugular processes enlarge, bent medially and become wider but don't protrude beyond the level of the occipital condyles (Fig 10).

The parietal part of the squamous part of the occipital bone is still connected with the parietal bone by the occipito-parietal suture (Fig 11). It has a well-developed triangular nuchal crest, which continues laterally with the temporal crest and has a welldeveloped external parietal crest, which is still separated from that of the parietal bone (Fig 11). The spheno-occipital suture is still not closed (Fig 12).

\section{Over 7.5 - 8 years of age of the camel:}

All sutures of the occipital with the neighboring bones complete its closure and the complete fusion of the ex-occipitals with each other is occurred (Figs. 13, 14, 15).

\section{Sphenoid bone (Os sphenoidale), (Os basisphenoidale) and (Os presphenoidale)}

\section{At 33.5 - $37 \mathrm{~cm}$ CVRL camel fetus- es:}

The sphenoid bone of the camel skull develops from six separate ossification centers investigated by normal dissection and different imaging techniques ; one for the basi-sphenoid 
body, one for the pre-shenoid body, two for the both wings of the basisphenoid and two for the both wings of the pre-shenoid (Figs 16, 21, 22, $23,25,26,27$ ).

The body of the basi-sphenoid is a short cylindrical mass, joined caudally and rostrally to the basilar part of the occipital bones and the body of the pre-sphenoid respectively by a thick layer of cartilage (Fig 16).

The wings of the basi-sphenoid extend lateral and somewhat dorsal to the body, they are irregular quadrilateral in outline and are smaller than that of the pre-sphenoid (Fig 16).

The rostral border of the wing of the basi-sphenoid forms with the caudal border of the pre-sphenoid a large formen, the orbito-rotun-dum (Fig 16). A rod like process protrudes from the ventral surface of the wings of the basi-sphenoid at the level of the junction of the basi-sphenoid with the presphenoid is called pterygoid process (Fig 16).

The body of the pre-sphenoid is short but longer than that of the basisphenoid (Fig 16).

The wing of the pre-sphenoid (orbitosphenoid) is quadrilateral in outline but larger than that of the basisphenoid (Fig16). The orbitosphenoid is observed in the transverse section of CT scan as a concave plate-like structure (Fig 22).

There is no evidence of fusion between the basi-sphenoid and pre-

J. Vet. Anat. sphenoid in this stage except at the mentioned above angle (Fig 16).

The body of the pre-sphenoid forms rostrally a central ridge, sphenoidal rostrum that appears clearly in the transverse section and three dimensions of CT scan (Fig 23).

\section{At 48.5 - $58 \mathrm{~cm}$ CVRL camel fetus- es:}

The wing of the basi-sphenoid is overlapped by the squamous part of the temporal bone and the parietal bone (Fig 17).

Caudal to the caudal border of the wing of the basisphenoid and lateral the root of the pterygoid process, there is a developed foramen called oval foramen for passage of the mandibular nerve (Fig 17).

\section{At 71 - $84 \mathrm{~cm}$ CVRL camel fetuses:}

The wing of the pre-spenoid has an aperture in the center, the optic foramen for the passage of the optic nerve (Fig18). The pterygoid process increase in length and the orbitorotundum and oval foramena become clear (Fig 18).

As a result of increasing of the ossification areas of the sphenoid bone, sutures with the neighboring bones become clear as spheno-squamous suture (between the caudal part of the dorsal border of the wing of the basisphenoid and the squamous part of the temporal bone), spheno-parietal suture (it unites the rostral part of the dorsal border of the wing of the basisphenoid and the dorso-caudal bor- 
der of the orbito-sphenoid with the parietal bone), spheno-frontal suture (between the dorsal border of the orbito-sphenoid and the frontal bone in sphenoidal notch) spheno-ethmoidal suture (between the rostral border of the orbito-sphenoid and the ethmoid bone) (Fig 18).

\section{At 2.5 - 3 years of age of the camel:}

All sutures of the sphenoid bone with the neighboring bones established its closure lines but not closed yet in this stage (Fig 12).

\section{At 7.5 - 8 years of age of the camel:}

All sutures of the sphenoid bone with the neighboring bones complete its closure except the suture between the presphenoid and the pterygoid bone, which remains opened (Fig 19).

\section{Over 12 years of age of the camel:}

All sutures of the sphenoid bone with the neighboring bones complete its closure even the suture between the pre-sphenoid and the pterygoid bone (Fig 20).

\section{Discussion}

Development of the ossification centers of the central skull base

It is interesting to note that Investigating the basicranium development by using the imaging techniques illustrates the double nature of the basioccipital that identified by kanan (1962). This is contrary to the observations made in Sus scrofa, (De Beer

J. Vet. Anat.
1985) and ovis (Kanan, 1957) where the basioccipital was seen to arise from a median main center in the caudal part of the basal plate.

This result revealed that the supraoccipital part of the occipital bone was ossified from double centers. It is contrary to the finding of kanan (1962) who described a single center for the supra-occipital part of horse-shoe shaped plate lying dorsal to the foramen magnum.

Ossification of the skull base of most mammals progresses in a sequencing pattern from caudal to rostral direction. Ossification begins in the occipital bone then proceeds to its basisphenoid and presphenoid portions (Kjaer and Fischer-Hansen, 1995 and Ricciardelli, 1995). The present work is in accordance with these observations and revealed that the same pattern also occurs in the suture closure of the camel skull base.

\section{Establishment of the synchon- droses}

The present study revealed that six sutures or synchondroses are related to the camel occipital bone:(1) dorsal intra-occipital synchondrosis (between the ex-occipital and squamous portions of the occipital bone), (2) ventral intra-occipital synchondrosis (between the basilar and ex-occipital portions of the occipital bone), (3) occipito-mastoidal suture (between the ex-occipital portion of the occipital bone and the mastoid portion of the temporal bone), (4) inter-exoccipital 
synchondrosis (between the two exoccipital parts),(5) petro-occipital synchondrosis (between the basal portion of the occipital bone and the petrous portion of the temporal bone), and (6) spheno-occipital synchondrosis (between the sphenoidal body and basal portion of the occipital bone).

In human, the same synchondroses are found with the exception of the inter-exoccipital synchondrosis that don't exist in addition to another synchondrosis called Kerckring - supraoccipital synchondrosis (between the Kerc-kning ossicle and the supraoccipital bone) (Madeline and Elster, 1995).

All cranial sutures and synchondrosis of the camel skull began and finished its closure after birth except the ventral intra-occipital synchondrosis which started and obliterated its closure before birth and it is thought to be necessary for supporting the skull on the vertebral column through the atlanto-occipital articulation.

The dorsal intra-occipital synchondrosis (named posterior intra-occipital synchondrosis in human) was the first one to be closed after birth as early as before 2.5 years of age. This synchondrosis (called the "obstetric hinge" by Budin, 1876) is thought to permit a certain amount of flexibility of the occipital region during passage through the birth canal (De Beer, 1985).

The spheno-occipital synchon-dnosis finished its closure at 7.5 - 8 years of age and this late closure is thought to J. Vet. Anat. be primarily responsible for the growth of the skull base after birth (Laine et al., 1990).

The present thesis revealed that five sutures or synchondroses are related to the camel sphenoid bone. The 5 sutures are (1) The spheno-occipital synchondrosis (2) inter-sphenoidal synchondrosis (between the presphenoid and basisphenoid), (3) sphenosqua-mosal suture (between the wings of the basisphenoid and the squamous temporal bone), (4) spheno-ethmoidal suture (bet-ween the orbito-sphenoid and ethmoid bones), and (5) fronto-sphenoidal suture (between the frontal bone and the orbitosphenoid).

These synchondroses are found in the human in addition to several synchondroses, which rapidly clo-sed at very early stage of the prenatal development (Madeline and Elster, 1995).

The inter-sphenoidal synchondroses like the spheno-occipital synchondrosis in which it didn't completely closes before 7.5 years of age. It is contrary to the finding of Madeline and Elster, (1995) in their study on the development of the human sphenoid bone where this synchondrosis started the closure in the early stage postnatal at 3 months of age and was completed at 5.3 years of age.

The spheno-squamosal suture of the camel skull had prolonged timing of closure, which is before $7.5-8$ years of age. It is similar to that of the human where this suture closed be- 
tween ages 2 and 6 years of age (Kodama, 1976).

\section{Conclusions}

1- The central skull base undergoes ossification during prenatal development, but cartilaginous synchondroses remains until early adulthood of life, when growth ceases.

2- The ventral intra-occipital synchondrosis is the only synchondrosis that started and obliterated its closure before birth and it is thought to be necessary for supporting the skull on the vertebral column through the atlantooccipi-tal articulation.

\section{References}

Couly, G. F, Coltey, P. M, Le Douarin, N. M. (1993): The triple origin of skull in higher vertebrates: a study in quail-chick chimeras. Development 117: 409-429.

De Beer, G. R. (1985): The development of the vertebrate skull. Re-print of 1937 edition, Oxford University Press. Chicago: University of Chicago Press.

Depew, M. J., Tucker, A. S., Sharpe, P. T. (2002): Craniofacial Development. In: Rossant, J., Tam, PPL. (Eds,), Mouse Development. Academic Press, San Diego, pp. 421-498.
El-Wishy, A. B., Hemeida, N. A., Omar, M. A., Mobarak, A. M., ElSayed, M. A. (1981): Functional changes in the pregnant camel with special reference to foetal growth. $\mathrm{Br}$ Vet J, 37:527-53.

Hillmann, D. J., 1975: Skull. In: Sisson and Grosman's The Anatomy of the Domestic Animals, 5th edn (R. Getty, ed.). Philadelphia, PA: WB Saunders Co.

Kanan, C. V. (1957): Observations on the Development of the Osteocranium of Ovis. Brit. Vet. J. 115: 185.

Kanan, C. V. (1962): Observations on the Development of the Osteocranium in Camelus Dromedarius. Acta Zoologica. Volume 43, Issue 2-3, pages 297-310.

Kjaer, I. and Fischer-Hansen, B. (1995): The adenohypophysis and the cranial base in early human development. J Craniofac Genet Dev Biol, 15:157-161.

Kodama, G. (1976): Developmental studies on the presphenoid, the body and the orbitosphenoid of the human sphenoid bone. In: Bosma, J. F., ed. Symposium on development of the basicranium. Publication no. (NIH) 76989. Bethesda, Md: U.S. Department of Health, Education and Welfare, 141-176. 
König, H. \& Liebich, H. G. (2004) : Veterinary Anatomy of Domestic Mammals. Schattauer, $\mathrm{GmbH}$, Stuttgart.

Laine, F. J., Nadel, L., Braun, I. F. (1990): CT and MR of the central skull base, 1: techniques, embryologic development, and anatomy. Radiographics. 10: 591-602.

Madeline L. A. and Elster A. D. (1995): Suture Closure In the Human Chondrocranium: CT Assessment. Radiology, 196:747-756.

Moore, W. J. (1981): The Mammalian Skull. Cambridge University Press: Cambridge/London/New York.

Noden, D. M. (1991): Vertebrate craniofacial development: The relation between ontogenetic process and morphological outcome. Brain Behav. Evol, 38: 190-225.

Rabigliata, D. S. (1924): The dentition of the camel. Govt. Press. Cairo, Egypt.
Ricciardelli, E. J. (1995): Embryology and anatomy of the cranial base. Clin Plast Surg, 22:361-372.

Scheuer, L. and Black, S. (2000: Developmental juvenile osteology. San Diego, Elsevier Academic Press.

Van Dermwe, N. J., Bezuidenhout, A. J. and Seegwers, Christina D. (1995): The skull and mandible of the African elephant (Loxodonta africana). On-derstepoort Journal of Veterinary research, 62: 245-260.

Williams, P. (1995): Gray's Anatomy, ed 38. Edinburgh, Churchill Livingstone.

Yoshida, T., Vivatbutsiri, P., Morriss-Kay, G., Saga, Y., Iseki, S. (2008): Cell lineage in mammalian craniofacial mesenchyme. Mech. Dev., 125: 797-808. 

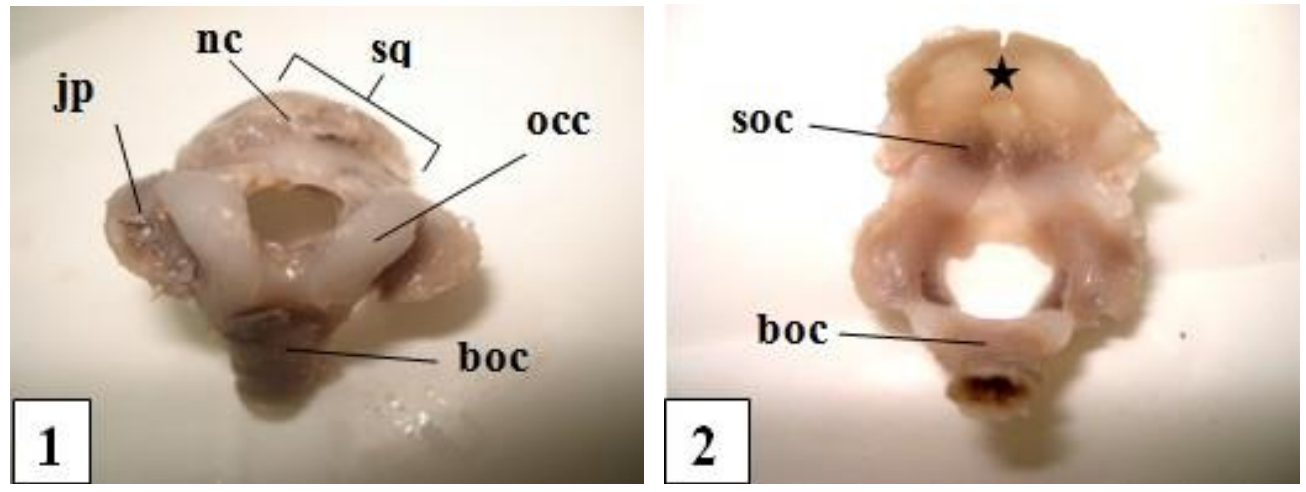

Fig (1): Caudo-ventral view of the occipital bone of a fetal skull with $33.5 \mathrm{~cm}$ CVR length shows the multiple ossification centers of the occipital bone. occ $=$ occipital condyle, $\mathrm{jp}=$ jugular process, $\mathrm{boc}=$ basioccipital part, $\mathrm{sq}=$ squamous part, $\mathrm{nc}=$ nuchal crest.

Fig (2): Cerebral view of the occipital bone of a fetal skull with $37 \mathrm{~cm}$ CVR length shows the double nature of the supra-occipital part (soc). boc = basioccipital part, black star $=$ parietal part of the squamous part.
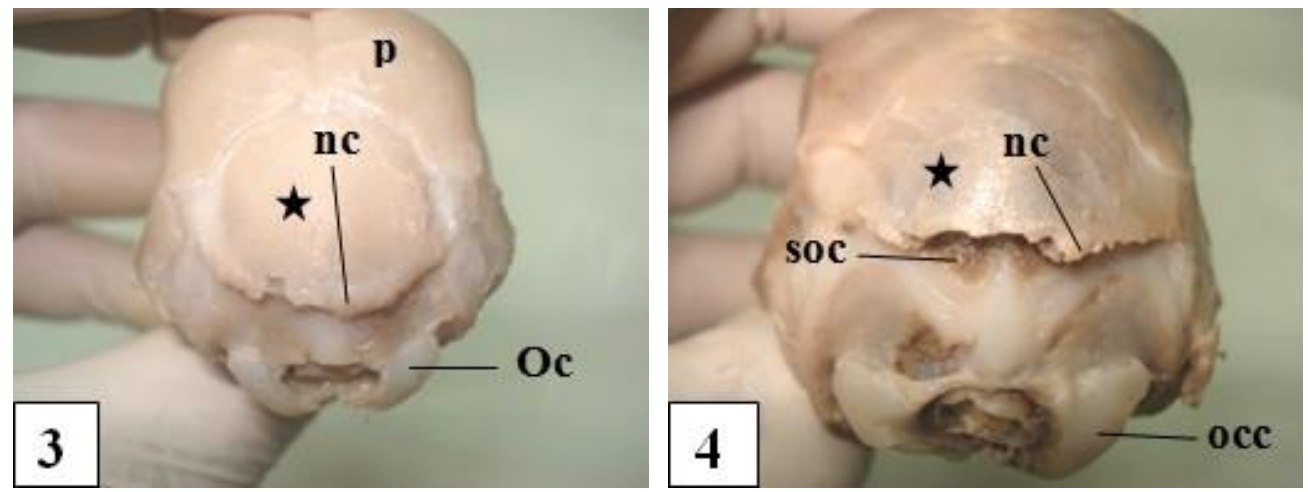

Fig (3): Caudal view of the occipital bone of a fetal skull with $37 \mathrm{~cm}$ CVR length shows the multiple ossification centers of the occipital bone. $p=$ parietal bone, occ $=$ occipital condyle, $\mathrm{nc}=$ nuchal crest. Black star $=$ parietal part of the squamous part of the occipital bone.

Fig (4): Caudal view of the occipital bone of a fetal specimen with $48.5 \mathrm{~cm}$ CVR length shows the developing ossified centers of the occipital bone. occ $=$ occipital condyle,, $\mathrm{soc}=$ supra-occipital part, $\mathrm{nc}=$ nuchal crest, $\mathrm{p}=$ parietal bone. black star $=$ parietal part of the squamous part of the occipital bone. 

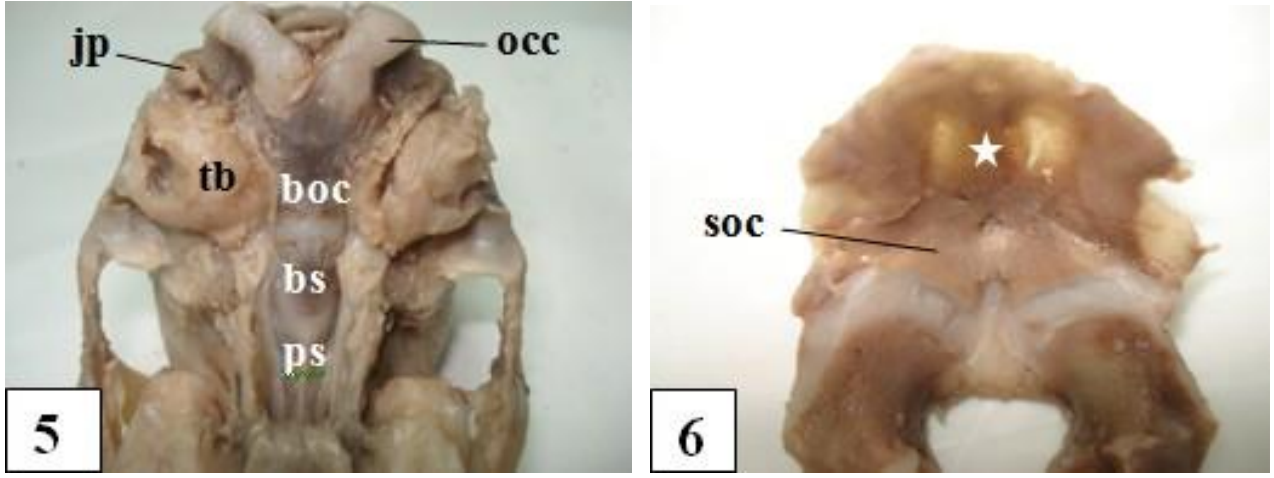

Fig (5): Ventral view of the skull of a fetal specimen with $48.5 \mathrm{~cm}$ CVR length shows the relation of the occipital, the sphenoid with each other. occ $=$ occipital condyle, $\mathrm{jp}=$ jugular process, $\mathrm{boc}=$ basioccipital part, $\mathrm{bs}=$ basisphenoid, $\mathrm{tb}=$ tympanic bulla .

Fig (6): Cerebral view of the occipital bone of a fetal specimen with $58 \mathrm{~cm}$ CVR length shows the fusion of the supra-occipital part (soc) with the parietal part of the squamous part (white star).
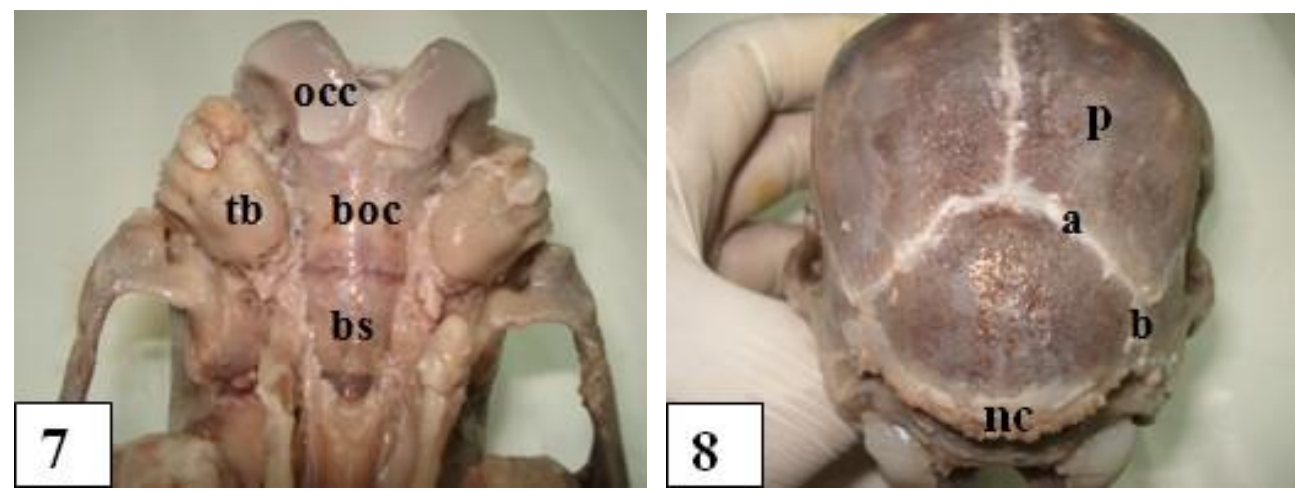

Fig (7): Ventral view of the skull of a fetal specimen with $84 \mathrm{~cm}$ CVR length shows the fusion between the occipital condyle (occ) and the basioccipital part (boc) and the ossification of the tympanic bulla (tb). bs = basisphenoid.

Fig (8): Dorsal view of the occipital and the parietal bone (p) of a fetal specimen with $84 \mathrm{~cm}$ CVR length show the developing sutures between them. a = occipitoparietal suture, $\mathrm{b}=$ squamo-occipital suture, $\mathrm{nc}=$ nuchal crest. 

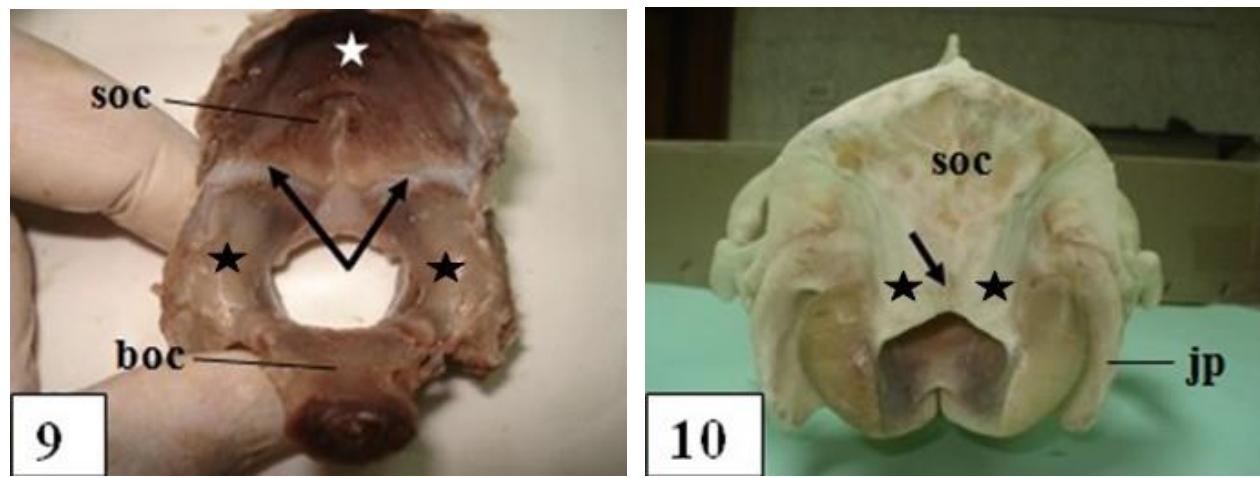

Fig (9): Cerebral view of the occipital bone of a fetal specimen with $84 \mathrm{~cm}$ CVR length shows that the ex-occipitals (black stars) unite with the supra-occipital part (soc) by transverse sutures (black arrows). boc $=$ basioccipital part, white star $=$ parietal part of the squamous part of the occipital bone.

Fig (10): Caudal view of the skull of the camel, 2.5 years of age shows that the supra-occipital part (soc) of the squamous part of the occipital bone fuses completely with the ex-occipitals (black stars) which they are still joining together by a sagittal suture (black arrow). The jugular processes (jp) enlarge, bent medially and become wider but don't protrude beyond the level of the occipital condyles
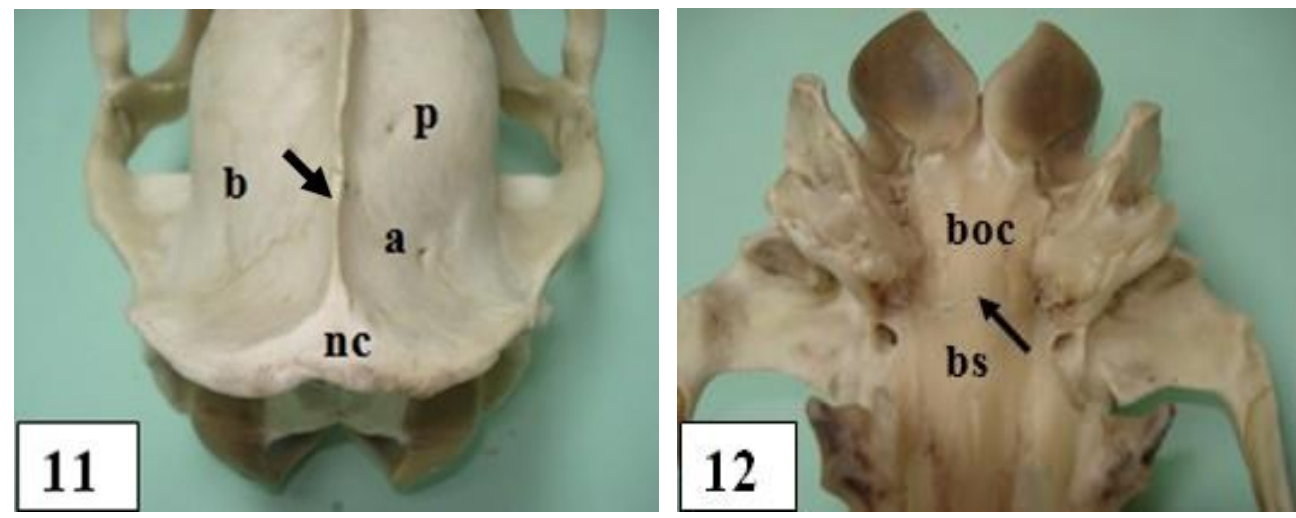

Fig (11): Dorsal view of the skull of the camel, 2.5 years of age shows that the occipito-parietal suture (a) and the squamous suture (b) don't close yet. $P=$ parietal bone, $\mathrm{nc}=$ nuchal crest. Black arrow $=$ external parietal crest

Fig (12): Ventral view of the skull of the camel, 2.5 years of age shows that the spheno-occipital suture (black arrow) is still not closed. boc $=$ basi-occipital part, bs = basi-sphenoid. 

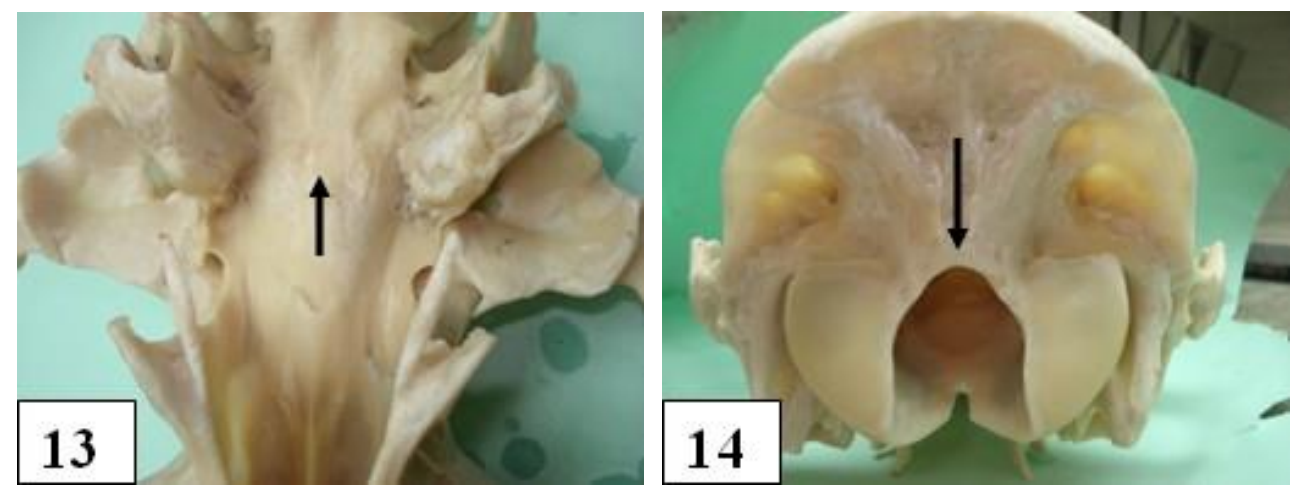

Fig (13): Ventral view of the skull of the camel, 7.5 - 8 years of age shows that the spheno-occipital suture (black arrow) is closed.

Fig (14): Caudal view of the skull of the camel, 7.5 - 8 years of age shows the complete fusion of the exoccipitals with each other (black arrow).
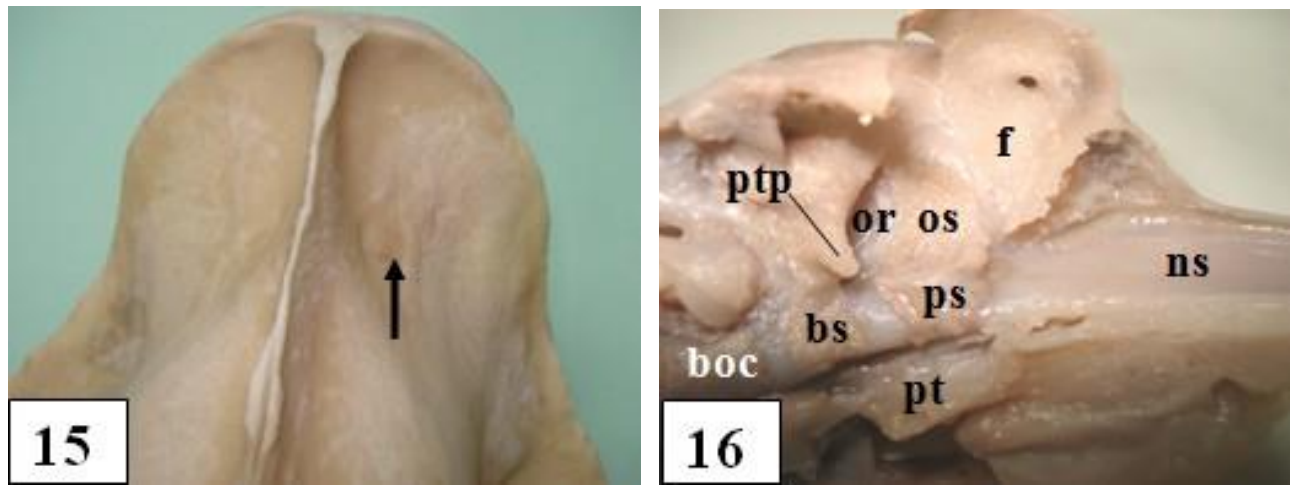

Fig (15): Dorsal view of the skull of the camel, 7.5 - 8 years of age shows the closure of the occipitoparietal suture (black arrow).

Fig. (16): Ventro-lateral view of the skull of a fetal specimen with $33.5 \mathrm{~cm}$ CVR length shows the centers of the sphenoid bone. boc $=$ basioccipital, bs = basisphenoid, $\mathrm{ps}=$ presphenoid, os $=$ orbito-sphenoid, ptp $=$ pterygoid process of the bs, $f=$ frontal bone (orbital plate), $n s=$ nasal septum, or = orbito-rotundum foramen, pt $=$ pterygoid bone. 

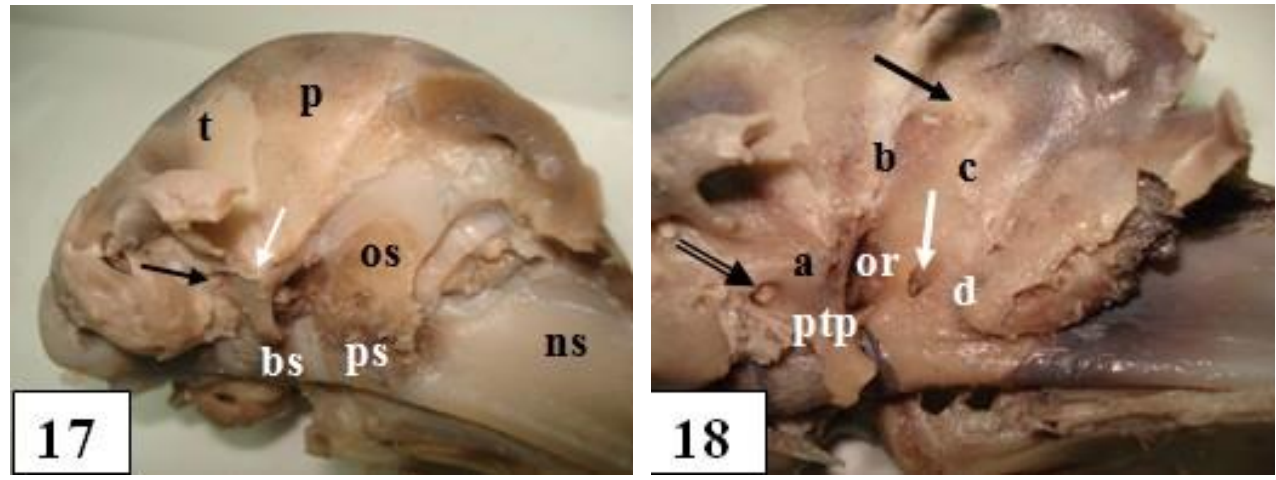

Fig (17): Ventro-lateral view of the skull of a fetal specimen with $48.5 \mathrm{~cm}$ CVR length shows the increasing of the area of ossification of the sphenoid bone. The wing of the basi-sphenoid is overlapped by the squamous part of the temporal bone $(t)$ and the parietal bone $(p)$ (white arrow). bs = basisphenoid, ps = presphenoid, os = orbitosphenoid, black arrow $=$ oval foramen. The orbital plate of the frontal bone is removed.

Fig (18): Ventro-lateral view of the skull of a fetal specimen with $84 \mathrm{~cm}$ CVR length shows the suture formation between the sphenoid and the temporal the parietal and the frontal bones and closure of the sphenoidal fontanelle (black arrow). The maxilla, the palatine and the vomer bones are removed. Spheno-squamous suture (a), spheno-parietal suture (b) spheno-frontal suture (c), spheno-ethmoidal suture (d). White arrow $=$ optic foramen. Open black arrow $=$ oval foramen. or $=$ orbitorotundum foramen. $\mathrm{ptp}=$ pterygoid process of the bs.
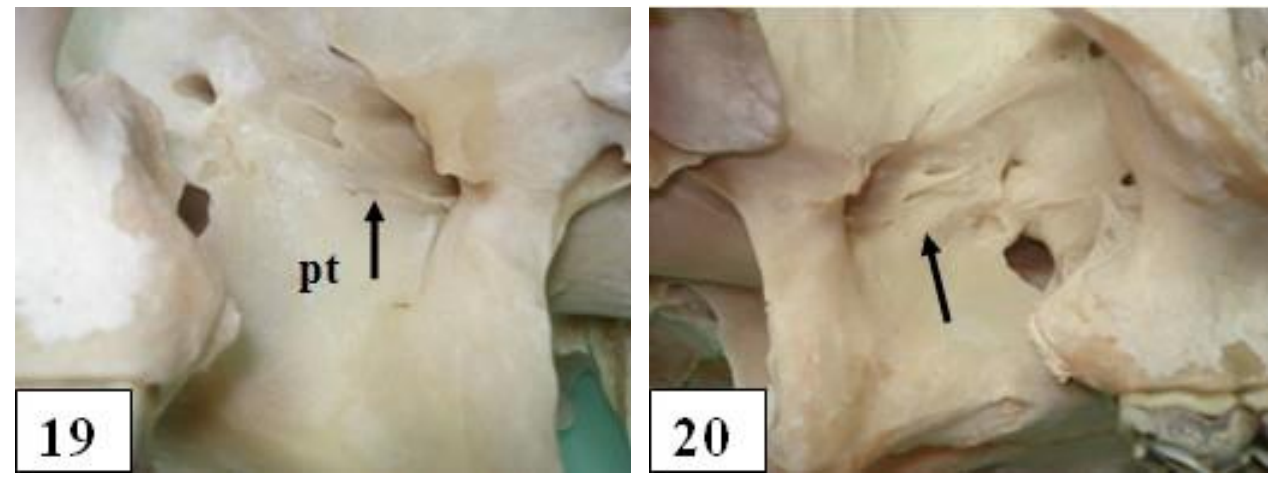

Fig (19): Lateral view of the skull of the camel, 7.5 - 8 years of age at the pterygopalatine fossa shows that all sutures of the sphenoid bone with the neighboring bones complete its closure except the suture between the presphenoid (ps) and the pterygoid bone (black arrow) remains opened. $\mathrm{Pt}=$ pterygoid bone.

Fig (20): Lateral view of the skull of the camel, over 12 years of age at the pterygopalatine fossa shows that all sutures of the sphenoid bone with the neighboring bones complete its closure even the suture between the presphenoid and the pterygoid bone (black arrow). 

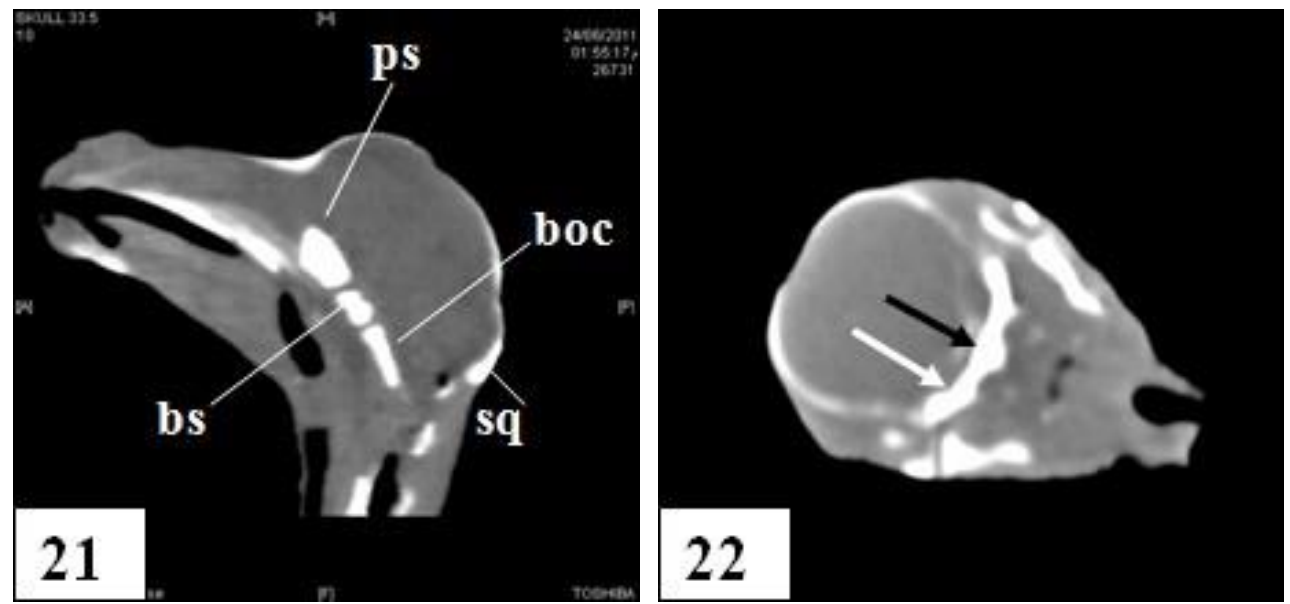

Fig (21): Sagittal CT scan of a fetal skull with $33.5 \mathrm{~cm}$ CVR length shows the ossification centers of the squamous part of the occipital bone (sq), the basioccipital (boc), the basisphenoid (bs), the presphenoid (ps).

Fig (22): Transverse CT scan of a fetal skull with $37 \mathrm{~cm}$ CVR length shows the body (black arrow) and the concave plate-like wing of the presphenoid (white arrow).
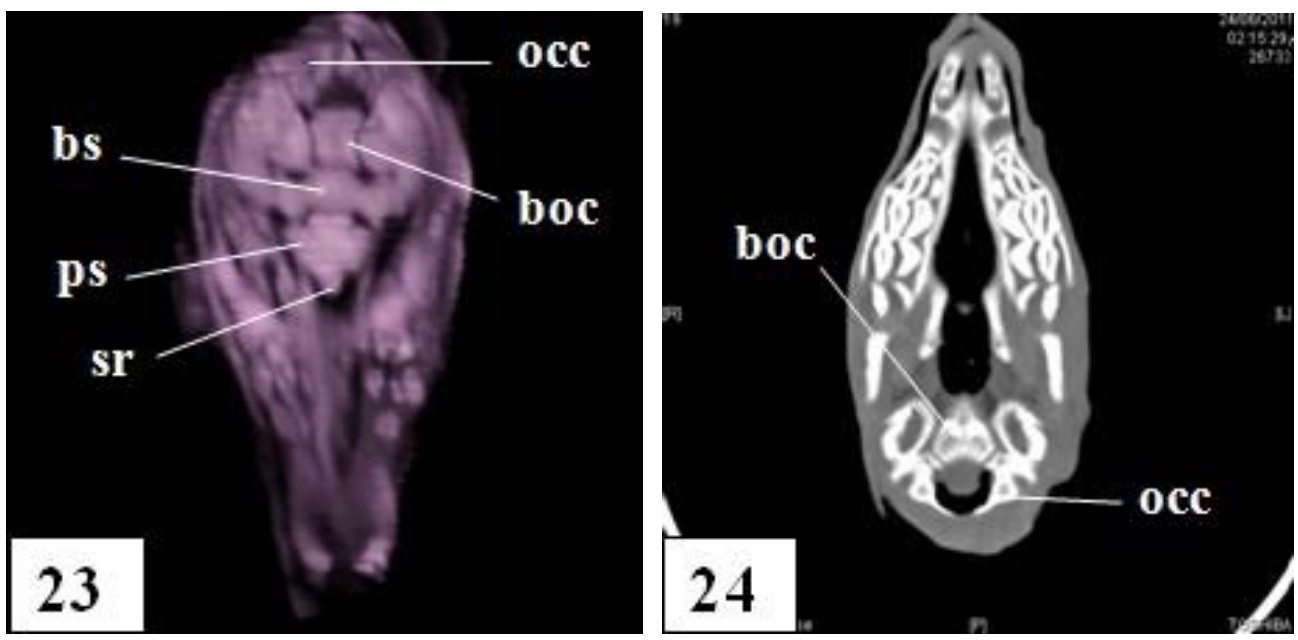

Fig (23): Volume 3D dimension CT scan of a fetal skull with $48.5 \mathrm{~cm}$ CVR length (ventral view) shows progressive ossification of the occipital condyle (occ), basioccipital (boc), basisphenoid (bs), presphenoid (ps). sr = sphenoid rostrum.

Fig (24): Coronal CT scan of a fetal skull with $71 \mathrm{~cm}$ CVR length illustrates the double nature of the basioccipital (boc). The fusion between the basioccipital (boc) the occipital condyle (occ) is not established. 


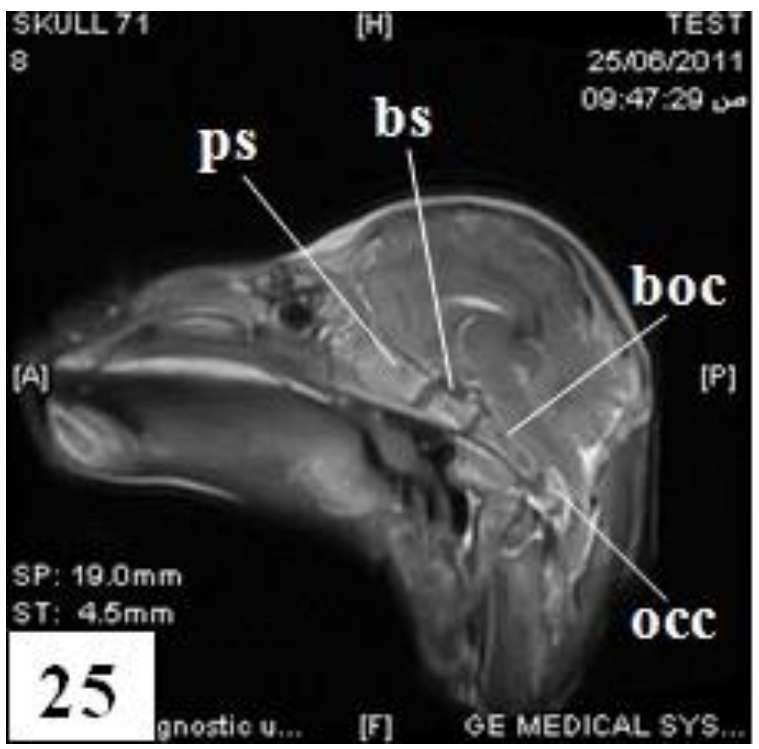

Fig (25): Sagittal MRI stir scan of a fetal skull with $71 \mathrm{~cm}$ CVR length shows the ossification centers of the occipital condyle (occ), the basioccipital (boc), the basisphenoid (bs), the presphenoid (ps).
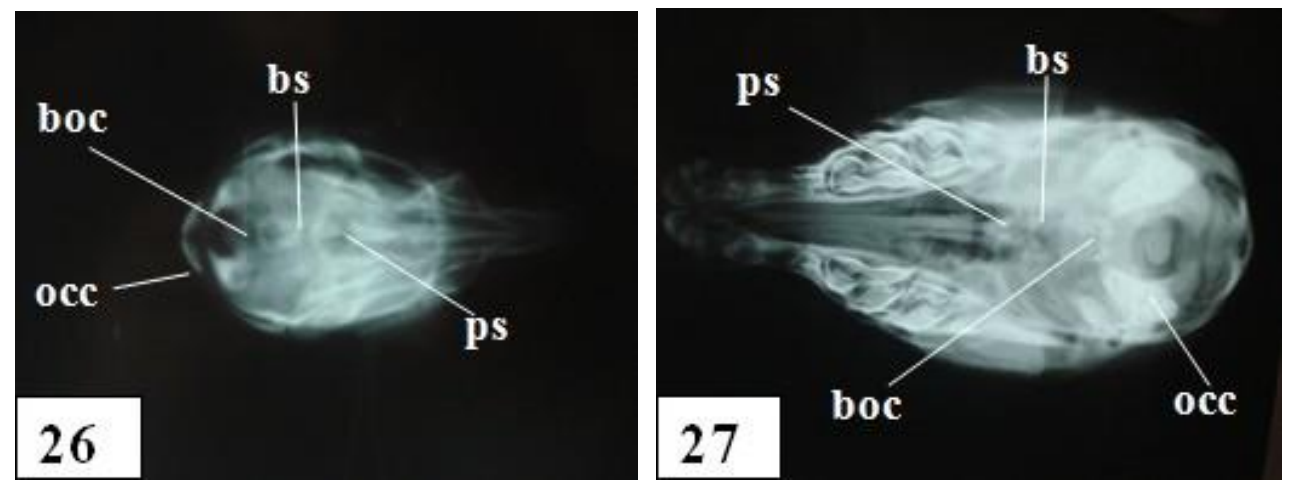

Fig (26): Dorsal view X ray of a fetal skull with $33.5 \mathrm{~cm}$ CVR length shows the ossification centers of the occipital condyle (occ), the basioccipital (boc), the basisphenoid (bs), the presphenoid (ps).

Fig (27): Dorsal view $X$ ray of a fetal skull with $71 \mathrm{~cm}$ CVR length shows the ossification centers of the occipital condyle (occ), the basioccipital (boc), the basisphenoid (bs), the presphenoid (ps). 